\title{
Teachers' Roles in Online Environments: How AI Based Techniques Can Ease the Shift Challenges from Face-to-Face to Distance Learning
}

\author{
https://doi.org/10.3991/ijet.v16i24.26367 \\ Aicha Marrhich $\left.{ }^{(}\right)$, Ichrak Lafram, Naoual Berbiche, Jamila El Alami \\ LASTIMI, ESTS, Mohamed V University, Rabat, Morocco \\ aichamarrhicheresearch.emi.ac.ma
}

\begin{abstract}
The Covid-19 emergency has brought a mandatory shift to online systems in the education sector worldwide. This document gives an overview about the online teaching challenges encountered from the teachers' point view, restitutes how the teacher's role in online settings can be determining in the successfulness of the learning experience and more importantly provides insights into Artificial Intelligence techniques that can solve the equation of transferring the role of teachers in face-to-face settings to distance learning environments.
\end{abstract}

Keywords-teacher's role, online teaching, AI techniques, online teaching challenges

\section{Introduction}

\subsection{The growing demand for online teaching after the pandemic of covid-19}

The Coronavirus pandemic (COVID-19) has had a big impact on how the world works. The education sector was one of the most affected sectors. In order to limit the influence of the virus and the pace of its spread, teachers and students all over the world were constrained to shift into online platforms to seek for education continuity. It was compulsory for both learners and educators to fit into the new learning environment rapidly. The Coronavirus has led to the closure of educational institutions to prevent the damage it was causing. The Covid-19 pandemic was responsible for the widest disruption of education systems of all time reaching roughly 1.6billion students [1]. Both teachers and learners were faced with multiple issues to cope with the new setting and were left no time for preparation. Many issues have arisen and the online education has become ever since a very trending topic that needs to be examined for an attempt to bring solutions that can ease the teaching and make learning online a flourishing experience. 
Paper-Teachers' Roles in Online Environments: How AI Based Techniques Can Ease the Shift..

\section{$1.2 \quad$ Research purpose}

The purpose of this study is to examine how important the teachers' role is in online environments, to look at the main differences between what is required from the educator to teach in online settings, the ultimate objective is to build on how Artificial Intelligence techniques can alleviate the teachers' workload and come up with solutions to make the online learning experience more successful. To put it differently, our aim is to attempt to provide answers to the following questions.

1. How important is the role of teachers in distance learning?

2. What are the issues that teachers face when teaching online?

3. What are the main differences between face-to-face teaching and distance teaching?

What changes in roles do teachers witness when shifting to distance learning?

4. What are the possible solutions that AI can offer to deal with the transition face-toface to distance learning?

\section{Online teaching challenges for teachers}

Many previous studies[2], [3], [4], [5], [6], [1], [7] have shown the overall challenges that online education faces, which impede the online learning process and lessens its efficiency as an alternative learning system. These challenges range from technological competencies, learner's expectations and readiness, technical infrastructure and skills, lack of student motivation, participation, the development and delivery via multimedia, assignment and assessment, the feedback, the communication barriers, time management, teaching styles, etc. In our study, we are going to shed light on the teacher's challenges in online environments and focus on the teacher's job process to determine how Artificial Intelligence techniques can come in handy.

\subsection{The importance of teachers' roles in building a successful online learning environment}

Online education is expected to become mainstream in the near future, it has been developing steadily and many studies evaluated the factors that affects its successfulness and so listed the major problems it faces [2], [3], [4] adaptability, technical issues, computer literacy, learning styles, motivation, feedback, teachers' workload, assessment and plagiarism. The role of teachers in an online learning environment is as important as their roles in a traditional one, in fact teachers play a determining role in a flipped classroom, online teaching and learning can only become thriving and efficient when teachers and learners have the same quality and amount of interaction as they do in traditional classrooms. Then only can the teacher's role be as conclusive as in traditional settings.

The online environment changes the teacher-student and student-student interaction, a study tried to investigate peer-led and teacher-led discussion groups in online environments[8], Warde, Stanworth, Ren and Warden stipulate that instructors can design 
a supportive environment and create social interactions equivalent to face to face classroom. Dong Yub Lee conducted a study[9] to investigate students' perceptions of the teacher's role in online learning environments. The findings showed that the teacher's affective capabilities have a direct positive impact on students' learning and outcomes, Ali[10] affirmed that promoting individualized learning can lead to a better learning experience. In his study, Carnevale, D [11] concluded that students look for the same criteria as in traditional courses such as a knowledgeable teacher who interacts with students. Further studies have shown that a learner performs better when they are given prompt feedback about their inquiries from their teachers[12].

Consistent studies have also shown that the instructor support emerges as the prime influential factor on how students perceive accomplishment targets and satisfaction[13].

\subsection{Understanding the differences between teachers' roles in face to face and flipped classrooms}

The teaching process in a traditional classroom can be summarized in the following tasks:

- Issuing educational content and giving the lesson

- Ensuring a positive safe and productive environment

- Engaging the students

- Checking for understanding

- Delivering personalized instruction

- Giving real time feedback

- Assigning homework

- Evaluating

- Grading tests

- Documenting students' progress

- Assessing attainment and achievement

One of the biggest challenges with teaching online is the role of the instructor. Berge, 1998 identified four roles of the teacher in online sessions: pedagogical, social, managerial and technical responsibilities. Pedagogical roles relate to the techniques of teaching; social roles refer to how instructors communicate with students; managerial roles consist of administrative and organizational tasks; and technical responsibilities represents technical aid provided to students. The dominant Educational objectives of online teaching should lie primarily in performing pedagogical tasks and ought to be of chief importance[14]. A prominent study regrouped the main roles of teachers in online teaching environments and listed them into the following main categories, M.-L. Hung et C. Chou [9] classified the teacher's role into five categories: Course designer and organizer, Discussion facilitator, Social supporter, Technology facilitator and Assessment designer. A further study classified these roles into the following: Pedagogical role, Managerial role, Technical role, affective role and differentiating role [15] 
The Figure 1 crosses the teacher's role in online teaching environment and the teacher's role in traditional teaching environments and shows where there is place for intersection and where Online teachers should bridge the gap to provide an advantageous learning experience, similar in structure to the traditional learning environment. Focus should tackle interaction, personalized feedback, checking content understanding.

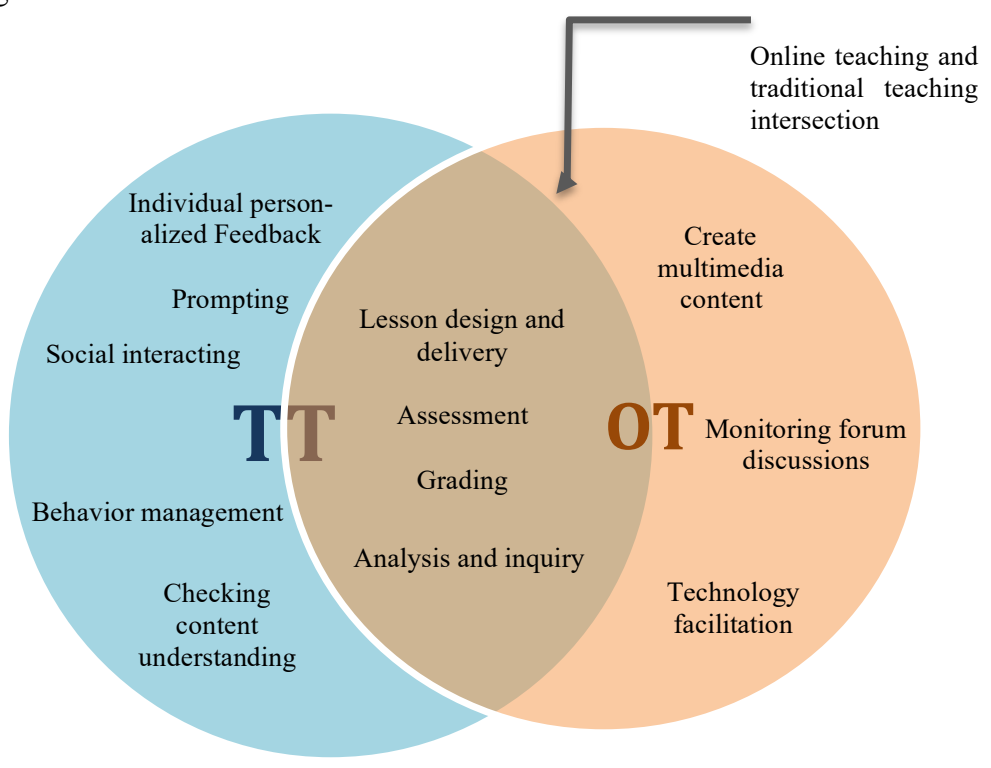

Fig. 1. crossing teachers' roles in traditional settings and online settings

\subsection{The challenges of online teaching from the teacher's point of view}

Post Covid-19 studies[5] have shown that during the Covid-19 pandemic, many problems arose, educational practices knew a variety of issues such as the lack of educator-student interaction, not being able to make a reliable assessment of learning, lack of knowledge about how to evaluate the learners' knowledge and skills, not being able to reach all the learning outcomes determined for learning, difficulty in providing feedback to students, and difficulty in teaching according to individual interests and abilities of the students. The transition to online learning and delivery during Covid-19 revealed that the teachers couldn't use the online methods with the purpose of reaching quality education. Teachers are responsible for incorporating learner friendly centered learning approaches to online environments[16].

The online teaching experience can be effective if it includes all the components of the teacher's role in traditional classrooms. The time and the dedication of teachers to implement online strategies determines the quality of the learning experience. [17]. Teaching online requires teachers to work to develop good quality material such as lecture videos, conferences, questionnaires, to read forum discussions and give appro- 
priate feedback and guidance to students when it's necessary, to assess and grade student's overall progress. However, many teachers are not prepared to integrate technology into their teaching approaches and spend a lot of time designing engaging courses to target the different learning styles of their students to issue and deliver a suitable understandable content. According to Tynan, Ryan \& Lamont-Mills[18], the number and complexity of teaching tasks online and the contact hours with students exceed the face to face ones. The use of ICT usually implies an increase in teaching tasks. The workload of teaching online practices leaves no room for them to interact and teachers have concern about how they can provide appropriate feedback to students, analyze their weakness, handle student behavior, and check individual understanding. Another concern is the versatile and changing aspect of technology, since technology is featured with learning, the workload is a consideration that imposes itself [19]. The next chapter of this paper will detail the contribution of AI to cope with the impediments that teachers face so as to establish better online teaching settings that draw near the traditional ones.

\section{The contribution of $\mathrm{AI}$ in assisting teachers in online settings}

In order to address the challenges that teachers face in distance learning and alleviate their workload; many studies attempted to liberate the obstacles to a successful teaching experience through the evaluation of the effectiveness of AI techniques. These studies suggested some possibilities to tone down part of the difficulties of online teaching in line with the structure and pedagogy of face-to-face learning environments, mainly to decrease the teacher's workload and help him help students with a better learning environment. The challenges are listed by category in Table 1.

Table 1. The challenges of the teacher's role in distance learning environments

\begin{tabular}{|l|c|}
\hline \multicolumn{1}{|c|}{ Teacher's roles Categories } & Challenges \\
\hline Discussion facilitator & Real time feedback in forum discussions \\
\hline Technology facilitator & Dealing with students' technical issues \\
\hline \multirow{3}{*}{ Social supporter } & Interaction teacher students \\
\cline { 2 - 2 } & Pauging the classroom temper \\
\cline { 2 - 2 } & Formative assessment \\
\hline \multirow{3}{*}{ Assessment designer } & Summative assessment \\
\cline { 2 - 2 } & Grading \\
\cline { 2 - 2 } Course designer and differentiator & Personalized content \& adapting content to students' level \\
\cline { 2 - 2 } & Coping with different learning styles \\
\hline
\end{tabular}

In the chapter below, we present some works that have been done in the field of AI techniques applied to online teaching, we tried to focus on the studies that attempted to solve the challenges relating to the teacher's role in online settings. The works are presented according to the teacher's roles' challenges in table 1 . 
Paper-Teachers' Roles in Online Environments: How AI Based Techniques Can Ease the Shift..

\subsection{Discussion facilitator}

Students' feedback can inform the teacher about the grey areas of students' content understanding, the analysis of real time feedback is a time-consuming task for online teachers.

Real time feedback in forum discussions. Studies[20] proposed to solve this issue by implementing a sentiment analysis based system that reads through students' feedback and summarizes the results to the instructor. Sentiment analysis is an application of natural language processing. Data from forums is collected, preprocessed, features are selected and machine learning techniques are applied to determine the level of understanding of the content. Sentiment Analysis is used to explore the open-ended questions to know students opinions using lexicon based and machine learning approaches so as to improve the teaching-learning process [21]. Other studies investigated the different levels of preprocessing with feature extraction and machine learning algorithms on student feedback[22].

In a recent study, Hsu et Huang[23] developed an educational intelligent question answering bot named Xiao-Shih to solve learner's questions immediately in seconds in a paid course named "Python for data science" on ShareCourse. Machine learning techniques such as NLP and random forest were used.

In some cases, students, in an online learning environment, face a lack of clarity and feel unable to move on with the course and so go seeking for information in forums. Zeng, Chaturvedi and Bhat studied this problem and proposed a trained model to predict confusion and detect urgency from forum discussions repositories[24].

\subsection{Technology facilitator}

Dealing with students' technical issues. A powerful type of computer-assisted instruction (CAI) based on extensive application of AI techniques in the name of SCHOLAR can prompt students, indicates when it doesn't understand them, detects misspellings and answers student's questions[25].

\subsection{Social supporter}

Educational research affirmed the presence of affect and emotions in classrooms, in fact emotions are related to students self-perceptions (encouragement, self-image)[29]. Online learning doesn't give students the opportunity to interact with their peers and with their teachers and doesn't allow teachers to provide a positive safe and productive environment nor does the online teaching environment leave space for learning through knowledge exchange neither with the instructor nor between peers.

Interaction teacher-student. A study [26]aimed at investigating the relationship between participation in online courses through synchronous interaction with a conversational virtual agent and the performance of the students. Log data with the amount of interaction with the agent and final grades were examined. The results showed that there is significant association between the agent discussion quality and the learner's outcomes. 
Peers' interaction. A research aimed to evaluate the use of deep learning-based natural generation (NLG) models (Recurrent Neural Network and Generative Pretrained Transformer 2) to provide human-like answers, the findings showed that some models could give supportive and contextual answers very similar to humans[27]. To support learners working in groups and sustain peer conversations, an exploratory study investigated the use of conversational agents to give collaborative support[28]. It indicated that conversational agents are beneficial in supporting collaborative learning, the conversational agent triggers student dialogue by making unrequested interventions based on academic frameworks.

Gauging the classroom temper. Several studies in the literature show that positive emotions improve learning. Further implementations of sentiment analysis with an affective intelligent tutoring system that analyzes students' feedback and provides information to the instructor to improve the teaching quality. At the end of an exercise, the system enquires about the student's opinion about the course and sends feedback to the teacher[30]. Another study[31] focused on the extraction of emotional knowledge of students' fora. The polarity and emotion are classified to assess the effectiveness of the learning environment and ameliorate tutors' instructional experience.

A study tried to use Intelligent Tutoring Systems(ITS) to grasp the student emotion and adapt environments through webcam facial expressions[32].

\subsection{Assessment designer}

Formative assessment. Formative assessment is a set of formal and informal evaluation procedures by teachers throughout the learning process aimed at modifying the teaching activities so as to ameliorate the achievement of students and address the issues they encounter immediately. A study demonstrates that the use of AI can help address the time and effort it requires to assess students with acceptable correlation with human grading in addition to saving time for the teacher and assisting him in finding correction mistakes. Students were asked to take part in the formative assessment tool during the course, a dashboard indicates the available exercises and the results, students can do the assignments and then invoke the tool to solve and suggest correction as well as give an estimation of the final grade.[33]

Summative assessment. Summative assessment takes place at the end of a pedagogical project/course in order to assess the level of skill acquisition and academic attainment of students. Vittorini et al. [33] implemented a tool that increases the performance of correction. In this experiment, a teacher was invited to correct 44 assignments, 21 were evaluated without the summative tool and 23 with the tool, the assignment evaluation time was reduced by approximately $43 \%$.

Grading. Grading essays is another highly demanding and time-consuming task for teachers, it can be challenging to do in large classes. A recent study explored automated grading systems using chatbots that ask students questions that need written replies, Unsupervised machine learning techniques were implemented to grade answers automatically. Findings concluded that the performance of the chatbot compared to human grading was satisfactory[34]. 
Paper-Teachers' Roles in Online Environments: How AI Based Techniques Can Ease the Shift..

\subsection{Course designer and differentiator}

Personalized content, adapting content to student's level. Personalized learning lies on tailoring the teaching process in alignment with the needs and preferences of students. Adaptive educational systems monitor the learner's learning characteristics and adjust the content offered accordingly[35]. An adaptive learning system can model the behavior of users and their level of knowledge, experience and personality traits. For this purpose, various AI techniques are used such as Fuzzy Logic, Decision tree, Bayesian networks, Neural networks, genetic algorithms, and Hidden Markov models to profiling students, facilitating the diagnostic process completion and to learn from student behavior.[36]

Coping with different learning styles. Adaptive educational systems seek to personalize the content and learning of students. Students learn through specific learning styles models (Felder \& Silverman's, Kolb's, VARK, and Honey \& Mumford). Some students are appealed by facts, data and experiments while others are more comfortable with theories, however, the online learning systems follow a one-size fits all principle, thus Artificial intelligence techniques can be used to determine students' learning styles. A study used a software system for AI based adaptive learning applied to a set of attributes that rely on the two models Felder \& Silverman and Kolb's to generate learning style models of students[37].

\section{Conclusion}

In this paper, we looked at teacher's roles challenges in distance teaching compared to traditional face-to-face teaching. An overview of AI techniques to help teachers help their students was presented according to the roles teachers play in the online teaching environment. There is no doubt that online education systems give a great number of interactions and generate a diversity of data that can be drawn on to infer pedagogically pertinent information, which when combined with AI techniques, can call for promising changes in easing the teacher's roles in online settings.

\section{$5 \quad$ References}

[1] P. Paudel, «Online Education: Benefits, Challenges and Strategies During and After COVID-19 in Higher Education», Int. J. Stud. Educ., vol. 3, no 2, p. 70-85, sept. 2020, https://doi.org/10.46328/ijonse.32

[2] Z. Berge, «Barriers To Online Teaching In Post-Secondary Institutions: Can Policy Changes Fix It?», Online J. Distance Learn. Adm., vol. 1, janv. 1998.

[3] J. Gillett-Swan, «The challenges of online learning: supporting and engaging the isolated learner», J. Learn. Des., vol. 10, no 1, Art. no 1, 2017. https://doi.org/10.5204/jld.v9i3.293

[4] I. R. Mathew et J. Ebelelloanya, «Open and Distance Learning: Benefits and Challenges of Technology Usage for Online Teaching and Learning in Africa», Commonwealth of Learning (COL) and Open University Malaysia (OUM), Working Paper, nov. 2016. Consulté le: août 16, 2021. [En ligne]. Disponible sur: http://oasis.col.org/handle/11599/2543 
Paper-Teachers' Roles in Online Environments: How AI Based Techniques Can Ease the Shift...

[5] A. Marrhich, I. Lafram, N. Berbiche, et J. E. Alami, «A Khan Framework-Based Approach to Successful MOOCs Integration in the Academic Context», Int. J. Emerg. Technol. Learn. IJET, vol. 15, no 12, p. 4-19, juin 2020. https://doi.org/10.3991/ijet.v15i12.12929

[6] F. Saltan, «Blended Learning Experience of Students Participating Pedagogical Formation Program: Advantages and Limitation of Blended Education», Int. J. High. Educ., vol. 6, $\mathrm{n}^{\circ}$ 1, p. 63, nov. 2016, https://doi.org/10.5430/ijhe.v6n1p63

[7] S. Palvia et al., «Online Education: Worldwide Status, Challenges, Trends, and Implications», J. Glob. Inf. Technol. Manag., vol. 21, no 4, p. 233-241, oct. 2018, https://doi.org /10.1080/1097198X.2018.1542262

[8] C. A. Warden, J. O. Stanworth, J. B. Ren, et A. R. Warden, «Synchronous learning best practices: An action research study», Comput. Educ., vol. 63, p. 197-207, avr. 2013, https://doi.org/10.1016/j.compedu.2012.11.010

[9] M.-L. Hung et C. Chou, «Students' perceptions of instructors' roles in blended and online learning environments: A comparative study», Comput. Educ., vol. 81, p. 315-325, févr. 2015, https://doi.org/10.1016/j.compedu.2014.10.022

[10] «Globalized E-Learning Cultural Challenges: 9781599043012: Education Books | IGI Global». https://www.igi-global.com/book/globalized-learning-cultural-challenges/429 (co nsulté le août 16, 2021).

[11] Carnevale, «Study assesses what participants look for in high-quality online courses», Chron. High. Educ., vol. A46, no 47, 2000.

[12] Fister, S, «10 ways to motivate online learners», Technol. Train., vol. 40-42, no 4, 2000.

[13] «Who or what contributes to student satisfaction in different blended learning modalities? Diep - 2017 - British Journal of Educational Technology - Wiley Online Library». https://bera-journals.onlinelibrary.wiley.com/doi/abs/10.1111/bjet.12431 (consulté le août 17, 2021).

[14] M. Kebritchi, A. Lipschuetz, et L. Santiague, «Issues and Challenges for Teaching Successful Online Courses in Higher Education: A Literature Review», J. Educ. Technol. Syst., vol. 46, no 1, p. 4-29, sept. 2017, https://doi.org/10.1177/0047239516661713

[15] D. Y. Lee, «Korean and foreign students' perceptions of the teacher's role in a multicultural online learning environment in Korea», Educ. Technol. Res. Dev., vol. 59, no 6, p. 913-935, déc. 2011, https://doi.org/10.1007/s11423-011-9219-0

[16] P. Paudel, «Online Education: Benefits, Challenges and Strategies During and After COVID-19 in Higher Education», Int. J. Stud. Educ., vol. 3, no 2, p. 70-85, sept. 2020, https://doi.org/10.46328/ijonse.32

[17] A. Ibrahim, A. Al Kaabi, et W. El Zaatari, «Teacher resistance to educational change in the United Arab Emirates», Int. J. Res. Stud. Educ., vol. 2, no 3, juill. 2013, https://doi.org /10.5861/ijrse.2013.254

[18] B. Tynan, Y. Ryan, et A. Lamont-Mills, «Examining workload models in online and blended teaching: Workload models in online and blended teaching», Br. J. Educ. Technol., vol. 46, no 1, p. 5-15, janv. 2015, https://doi.org/10.1111/bjet.12111

[19] H. J. Choi et J.-H. Park, «Difficulties that a Novice Online Instructor Faced: A Case Study», Q. Rev. Distance Educ., vol. 7, no 3, p. 317-322, 2006.

[20] N. Altrabsheh, M. Cocea, et S. Fallahkhair, «Sentiment Analysis: Towards a Tool for Analysing Real-Time Students Feedback», in 2014 IEEE 26th International Conference on Tools with Artificial Intelligence, Limassol, Cyprus, nov. 2014, p. 419-423. https://doi.org/10.1109/ICTAI.2014.70

[21] G. S. Chauhan, P. Agrawal, et Y. K. Meena, «Aspect-Based Sentiment Analysis of Students' Feedback to Improve Teaching-Learning Process», in Information and Communication 
Paper-Teachers' Roles in Online Environments: How AI Based Techniques Can Ease the Shift...

Technology for Intelligent Systems, vol. 107, S. C. Satapathy et A. Joshi, Éd. Singapore: Springer Singapore, 2019, p. 259-266. https://doi.org/10.1007/978-981-13-1747-7 25

[22] Mohammad Aman Ullah, «Sentiment Analysis of students feedback: A study towards optimal tools», International Workshop On Computational Intelligence, Bangladesh, 2016.

[23] H.-H. Hsu et N.-F. Huang, «Xiao-Shih: The Educational Intelligent Question Answering Bot on Chinese-Based MOOCs», in 2018 17th IEEE International Conference on Machine Learning and Applications (ICMLA), Orlando, FL, déc. 2018, p. 1316-1321. https://doi.org /10.1109/ICMLA.2018.00213

[24] Ziheng zeng, Snigdha Chaturvedi, et Suma Bhat, «Learner affect through the looking Glass: Characterization and detection of Confusion in online courses», Proc. 10th Int. Conf. Educ. Data Min.

[25] J. Carbonell, «AI in CAI: An Artificial-Intelligence Approach to Computer-Assisted Instruction», IEEE Trans. Man Mach. Syst., vol. 11, no 4, p. 190-202, déc. 1970, https://doi.org/10.1109/TMMS.1970.299942

[26] D. Song, M. Rice, et E. Y. Oh, «Participation in Online Courses and Interaction With a Virtual Agent», Int. Rev. Res. Open Distrib. Learn., vol. 20, no 1, févr. 2019, https://doi.org/10.19173/irrodl.v20i1.3998

[27] Chebglu Li et Wanli Xing, «Natural Language Generation Using Deep Learning to Support MOOC Learners», International Journal of Artificial Intelligence in Education, p. 186-214, 2021. https://doi.org/10.1007/s40593-020-00235-x

[28] Tegos S. et al., «Enriching Synchronous Collaboration in Online Courses with Configurable Conversational Agents», Springer, Cham. https://doi.org/10.1007/978-3-030-49663-0 34, 2020.

[29] A. D. Rowe, «Feelings About Feedback: The Role of Emotions in Assessment for Learning», in Scaling up Assessment for Learning in Higher Education, vol. 5, D. Carless, S. M. Bridges, C. K. Y. Chan, et R. Glofcheski, Éd. Singapore: Springer Singapore, 2017, p. 159-172. https://doi.org/10.1007/978-981-10-3045-1 11

[30] M. L. Barron-Estrada, R. Zatarain-Cabada, R. Oramas-Bustillos, et F. Gonzalez-Hernandez, «Sentiment Analysis in an Affective Intelligent Tutoring System», in 2017 IEEE 17th International Conference on Advanced Learning Technologies (ICALT), Timisoara, Romania, juill. 2017, p. 394-397. https://doi.org/10.1109/ICALT.2017.137

[31] A. F. Gkontzis, C. V. Karachristos, C. T. Panagiotakopoulos, E. C. Stavropoulos, et V. S. Verykios, «Sentiment Analysis to Track Emotion and Polarity in Student Fora», in Proceedings of the 21st Pan-Hellenic Conference on Informatics, Larissa Greece, sept. 2017, p. 1-6. https://doi.org/10.1145/3139367.3139389

[32] Wellton Costa de Oliveira, Ernani Gottardo, et Andrey Ricardo Pimentel, «Changes of affective states in intelligence tutoring system to improve feedbacks through low-cost and open electroencephalogram and facial expression», 16th International Conference, ITS 2020, Athens, Greece, déc. 08, 2020. https://doi.org/10.1007/978-3-030-49663-0 55

[33] P. Vittorini, S. Menini, et S. Tonelli, «An AI-Based System for Formative and Summative Assessment in Data Science Courses», Int. J. Artif. Intell. Educ., vol. 31, no 2, p. 159-185, juin 2021, https://doi.org/10.1007/s40593-020-00230-2

[34] I. G. Ndukwe, B. K. Daniel, et C. E. Amadi, «A Machine Learning Grading System Using Chatbots», in Artificial Intelligence in Education, vol. 11626, S. Isotani, E. Millán, A. Ogan, P. Hastings, B. McLaren, et R. Luckin, Éd. Cham: Springer International Publishing, 2019, p. 365-368. https://doi.org/10.1007/978-3-030-23207-8 67

[35] S. Oxman, and W. Wong, «White paper: Adaptive Learning Systems», DeEducation Group Integr. Educ. Solut., 2014. 
Paper-Teachers' Roles in Online Environments: How AI Based Techniques Can Ease the Shift...

[36] K. Colchester, H. Hagras, D. Alghazzawi, et G. Aldabbagh, «A Survey of Artificial Intelligence Techniques Employed for Adaptive Educational Systems within E-Learning Platforms», J. Artif. Intell. Soft Comput. Res., vol. 7, no 1, p. 47-64, janv. 2017, https://doi.org 10.1515/jaiscr-2017-0004

[37] R. Bajaj et V. Sharma, «Smart Education with artificial intelligence based determination of learning styles», Procedia Comput. Sci., vol. 132, p. 834-842, 2018, https://doi. org/10.1016/j.procs.2018.05.095

\section{Authors}

Aicha Marrhich received the Engineering degree in Computer Science from Ecole Mohammadia d'Ingénieurs, Rabat, Morocco in 2011. Her research interests include elearning, artificial intelligence applied to the education realm.

Ichrak Lafram received his Engineering degree in Computer Science from the Institut National des Statistiques et des Sciences Appliquées, Rabat Morocco in 2010. His research interests include big data and artificial intelligence, machine learning, neural networks.

Naouale Berbiche is a research director at Lab. of Systems Analysis, Information Processing and Integrated Management. Her interests include artificial neural networks, e-learning in higher education, UML models.

Jamila El Alami is a research director at Lab. of Systems Analysis, Information Processing and Integrated Management. She is also the head of the Scientific and technical affairs Department at The National Centre for Scientific and Technical Research in Morocco. Her interests include machine learning, blended learning experience.

Article submitted 2021-08-19. Resubmitted 2021-11-03. Final acceptance 2021-11-05. Final version published as submitted by the authors. 